\title{
E-IMR: e-health added to face-to-face delivery of Illness Management \& Recovery programme for people with severe mental illness, an exploratory clustered randomized controlled trial
}

\author{
Titus A. A. Beentjes ${ }^{1,2,3^{*}}$ (D) Peter J. J. Goossens ${ }^{3,4}$, Hester Vermeulen', Steven Teerenstra ${ }^{5}$,
} Maria W. G. Nijhuis-van der Sanden ${ }^{1}$ and Betsie G. I. van Gaal ${ }^{1,6}$

\begin{abstract}
Background: E-mental health holds promise for people with severe mental illness, but has a limited evidence base. This study explored the effect of e-health added to face-to-face delivery of the Illness Management and Recovery Programme (e-IMR).

Method: In this multi-centre exploratory cluster randomized controlled trial, seven clusters $(n=60 ; 41$ in intervention group and 19 in control group) were randomly assigned to e-IMR + IMR or IMR only. Outcomes of illness management, self-management, recovery, symptoms, quality of life, and general health were measured at baseline $\left(T_{0}\right)$, halfway $\left(T_{1}\right)$, and at twelve months $\left(T_{2}\right)$. The data were analysed using mixed model for repeated measurements in four models: in 1) we included fixed main effects for time trend and group, in 2) we controlled for confounding effects, in 3) we controlled for interaction effects, and in 4) we performed sub-group analyses within the intervention group.

Results: Notwithstanding low activity on e-IMR, significant effects were present in model 1 analyses for self-management $(p=.01)$ and recovery $(p=.02)$ at $T_{1}$, and for general health perception $(p=.02)$ at $T_{2}$, all in favour of the intervention group. In model 2, the confounding covariate gender explained the effects at $T_{1}$ and $T_{2}$, except for self-management. In model 3 , the interacting covariate non-completer explained the effects for self-management $(p=.03)$ at $T_{1}$. In model 4 , the sub-group analyses of e-IMR-users versus non-users showed no differences in effect.

Conclusion: Because of confounding and interaction modifications, effectiveness of e-IMR cannot be concluded. Low use of e-health precludes definite conclusions on its potential efficacy. Low use of e-IMR calls for a thorough process evaluation of the intervention.
\end{abstract}

Trial registration: The Dutch Trial Register (NTR4772)

Keywords: Severe mental illness, E-mental health, Illness management and recovery

\footnotetext{
* Correspondence: titus.beentjes@radboudumc.nl

${ }^{1}$ Titus Beentjes, IQ Healthcare, Radboud University Medical Center, Radboud

Institute for Health Sciences, PO Box 9101, 6500, HB, Nijmegen, the

Netherlands

${ }^{2}$ Center for Nursing Research, Saxion University of Applied Science,

Deventer/Enschede, the Netherlands

Full list of author information is available at the end of the article
}

(c) The Author(s). 2018 Open Access This article is distributed under the terms of the Creative Commons Attribution 4.0 International License (http://creativecommons.org/licenses/by/4.0/), which permits unrestricted use, distribution, and reproduction in any medium, provided you give appropriate credit to the original author(s) and the source, provide a link to the Creative Commons license, and indicate if changes were made. The Creative Commons Public Domain Dedication waiver (http://creativecommons.org/publicdomain/zero/1.0/) applies to the data made available in this article, unless otherwise stated. 


\section{Background}

In spite of the growing interest in e-mental health, evidence for the effectiveness of e-health for people with a severe or serious mental illness (SMI) is limited $[1,2]$. Naslund et al. [2] found that e-health interventions for people with SMI have high feasibility and acceptability. Van der Krieke et al. [3] found that people with psychotic disorders were able and willing to engage in e-health, and found larger effects for medication management [3]. However, one should be cautious about drawing conclusions regarding the effectiveness $[2,3]$. E-health is used in a wide range of interventions for people with SMI on (1) illness self-management and relapse prevention, (2) promoting adherence to medications and/or treatment, (3) psycho-education, supporting recovery, and promoting health and wellness, and (4) symptom monitoring [2]. E-health interventions make use of personal digital assistance, medication tracking devices, home monitoring systems, smartphone applications, SMS, and web-based interventions [2].

Also in general mental health, e-health approaches show great potential and offer the possibility of expanding access to care while being economically and socially efficient [4]. But e-health interventions in mental health have high attrition rates [5]. The addition of face-to-face contact to e-health is supposed to increase the therapeutic relation and prevent attrition [6]..In the case of people with SMI, e-health components could be added to an evidence-based face-to-face recovery-oriented intervention. Such an intervention is the Illness Management \& Recovery programme (IMR) [7]. The IMR is a standardized curriculum-based approach designed to provide people with SMI the information and skills necessary for managing their illnesses effectively and working towards achieving personal recovery goals. In addition to the standard face-to-face delivery of the IMR, an e-health intervention (e-IMR) was designed which follows the IMR-curriculum, and was further developed with the end-users of the intervention [8]. The aim of this study was to explore the effect of the e-IMR for people with SMI who were referred to the Illness Management \& $\mathrm{Re}-$ covery programme.

\section{Methods}

The e-IMR was tested in an exploratory multi-centre cluster randomized controlled trial. According to the Medical Research Council guidance [9], an exploratory trial evaluated an intervention before testing it in a confirmative trial. In this study, a cluster was a subdivision of a mental health institute. The cluster randomization prevented contamination between the intervention and control group participants. Data were collected at baseline, halfway and endpoint. The inclusion period was between January and October 2015. Data collecting lasted until October 2016.

Eligible clusters delivered the IMR-programme as a whole package with an experienced trainer-couple meaning that at least one trainer completed the IMR-total-training organized by the Dutch IMR-network and executed at least the first five modules of the IMR-programme before starting the IMR-programme in the trial.

\section{Trial monitoring}

An employee of the 'Radboudumc Technology Center Clinical Studies' monitored the process of trial administration. The administration of Trial Master Files, both paper as well as computerized files, was independently checked for completeness and accuracy.

\section{Randomization}

A statistician generated a randomization schedule using Statistical Analysis System ${ }^{\circ}$, version 9.4. The allocation to the intervention or control group was communicated after the participating institutional board provided their consent to participation. Because of the nature of the intervention, blinding was not possible.

\section{Sample size}

Because of the exploratory character of this study, a power calculation was considered unnecessary.

\section{Participants}

Eligible participants met the following criteria: above 18 years of age; capable of giving informed consent; and meeting the Dutch SMI criteria according to Delespaul [10] (being diagnosed with a psychiatric disorder that causes, and is due to, serious impairments in social and/ or occupational functioning which lasts longer than at least a couple of years and necessitates coordinated multidisciplinary care. Persons who were overwhelmed by disability, including dependence, denial, confusion, anger or despair, were excluded from participating.

\section{Care as usual}

All participants, in both the intervention and control group, received care consisting of extensive inpatient and/or outpatient psychiatric treatment including case management. They also received the IMR-programme, which was provided in weekly, $2-\mathrm{h}$, face-to-face group sessions according to the Dutch version of the IMR 3.0 programme [11] using the hard-copy version of 11 modules.

\section{Intervention}

On top of this care as usual, participants in the intervention group had the opportunity to use the e-IMR intervention 
[8]. The e-IMR intervention started with a 'welcome page' explaining the use of e-IMR and leading participants to the 11 modules. The e-IMR intervention included the same fill-in forms as in the hard-copy version of the IMR-programme. E-IMR added illustrative videos showing peer testimonials to encourage participants to talk more freely about themselves and to take steps in their recovery process. E-IMR also added problem-solving forms at the end of each module, registration of successful coping strategies, and a symptom-monitoring page.

The e-IMR was introduced to the trainers and participants of the intervention group by the first researcher in the second group session. Individuals who did not provide informed consent were allowed to join the e-IMR without participating in the research. The trainer-couples were supported in learning how to support participants in the use of e-IMR; how to install e-IMR on a computer in the session room and how to use e-IMR during the sessions.

In e-IMR, the registration forms of successful coping strategies and the symptom-monitoring page were introduced after the second module 'practical facts about mental illnesses'. Weekly emails with a link to the e-IMR platform led the participants to the symptom-monitoring page. After closing each module, one of the trainers gave feedback to the participants via the platform and guided the participants to the next module.

\section{Data collection}

Data were collected in face-to-face interviews by the researcher or a researcher assistant at three time points: at baseline, a week before starting the IMR-programme $\left(\mathrm{T}_{0}\right)$; halfway, after completing the 5 th module $\left(\mathrm{T}_{1}\right)$; and endpoint, at least a week after finishing the IMRprogramme $\left(T_{2}\right)$. The data were recorded on paper and later transferred into a LimeSurvey ${ }^{\circ}$ [12] database. The original recorded data as well as the transferred were double-checked for accuracy and completeness.

\section{Outcome measures}

At baseline, independent demographic and clinical characteristics were recorded. At all three time points, six dependent outcome domains were gathered.

At $\mathrm{T}_{0}$ the following participant characteristics were collected: age, gender, physical comorbidities, treatment history, cultural background, social economic status, education level, computer/Internet availability and use. At $\mathrm{T}_{0}$, the participant's case manager provided their diagnostic classification according to the Diagnostic and Statistical Manual of Mental Disorders, 4th edition.

The participant's ability to manage their illness was measured with the consumer version of the Illness Management \& Recovery Scales (IMRS), consisting of 15 items [13]. The response anchors, on a five-point
Likert scale (1-5) vary depending on the item. The IMRS total-up score ranged between 15 and 75. The IMRS' Cronbach's alpha is .55-.83 [14-17].

The participants' self-management ability, which refers to the individual's knowledge, skill and confidence for managing his/her own health and healthcare, was measured with the Patients Activation Measure (PAM-13) [18], consisting of 13 items. The response anchors on a five-point scale, vary from not applicable (0), 'strongly disagree' (1) to 'strongly agree' (4). The term 'doctor' in the items five and six was explained as their mental health clinician, which includes a nurse and/or case manager. Raw scores were transformed into standardized activation scores ranging between 0 and 100. The PAM-13's Cronbach's alpha is .84-.88 [19-22].

The Mental Health Recovery Measure (MHRM) assessed the participants' progress in their recovery process. The MHRM consists of 30 items with response anchors, on a five-point scale, varying from 'strongly disagree' (0) to 'strongly agree' (4), and 'neutral' (2) in between [23]. The MHRM total-up scores ranged between 0 and 120. The MHRM's Cronbach's alpha is .93 [24].

The participants estimated the level of burden of symptoms they experienced using the Brief Symptom Inventory (BSI), consisting of 53 items [25]. The response anchors, on a five-point scale, vary from 'not at all' (0) to 'extremely' (4). The mean BSI scores ranged between 0 and 4 . A negative time trend for the BSI means a reduced level of burden. The BSI's Cronbach's alpha is .96 [26].

The participants' subjective satisfaction with life was measured with the Manchester Short Assessment of quality of life (MANSA), consisting of 12 items [27]. The response anchors on a seven-point scale vary from 'couldn't be worse' (1) to 'couldn't be better' (7). The mean MANSA score ranged between 1 and 7 . The MANSA's Cronbach's alpha is .81 [28].

The participants' general health status was measured with the Rand 36-item Health Survey (Rand-36), consisting of eight subscales: physical functioning (Rand$\mathrm{PF}$ ), social functioning (Rand-SF), role limitations due to a physical (Rand-RLPP) and an emotional problem (Rand-RLEP), mental health (Rand-MH), vitality (Rand-V), pain (Rand-P), and general health perception (Rand-GHP) [29]. The response anchors vary between yes/no to Likert scales with three, five, and six options. Raw scores of all the concepts were transformed into scores ranging between 0 and 100. The Cronbach's alpha of Rand-36's eight concepts are .71 and .92 [30].

The extent of participants' activity on the e-IMR platform was determined by counting the number of completed modules and number of log-ins. An e-IMR user is identified by having completed at least module one or having logged in at least five times. Users were regarded 
as having had the opportunity to benefit from the e-IMR.

As in other studies on IMR [31], participants who attended the face-to-face IMR programme sessions less than $50 \%$ were considered to be non-completers. In our study, this resembles stopping the IMR programme before $\mathrm{T}_{1}$.

\section{Statistical methods}

The Statistical Package for the Social Sciences ${ }^{\circ} 23$ [32] was used to carry out the analyses. Mixed model multilevel regression analyses were used to examine the main effects on the outcome measures, taking into account clustering of participants and repeated measures. This method automatically uses the 'missing at random' assumption to handle missing data. Random effects on cluster, trainer-couple, and individual participants nested within the cluster were included in the model. Model 1 included fixed main effects for time trend and group. The analyses were executed according to the intention-to-treat principle to prevent bias caused by the loss of participants [33] and to reflect the normal practice [34] of high attrition rates in treatments of people with SMI [7] and e-health [5].

Post hoc analyses of effect differences were performed to control for covariates. We considered the covariate gender to be a potential confounder because of its known differences in exposure and reactions to stress and health [35]. The covariate was included in model 2, controlling for confounding time trend effects.

In model 3, covariates were included that were expected to interact with the effect differences.

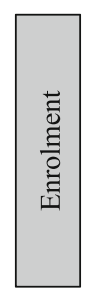

Clusters assessed for eligibility $(\mathrm{n}=15)$

Clusters excluded $(\mathrm{n}=8)$

- Not meeting inclusion criteria $(\mathrm{n}=2)$

- Declined to participate $(n=6)$

- Not starting an IMR-programme group $(\mathrm{n}=2)$

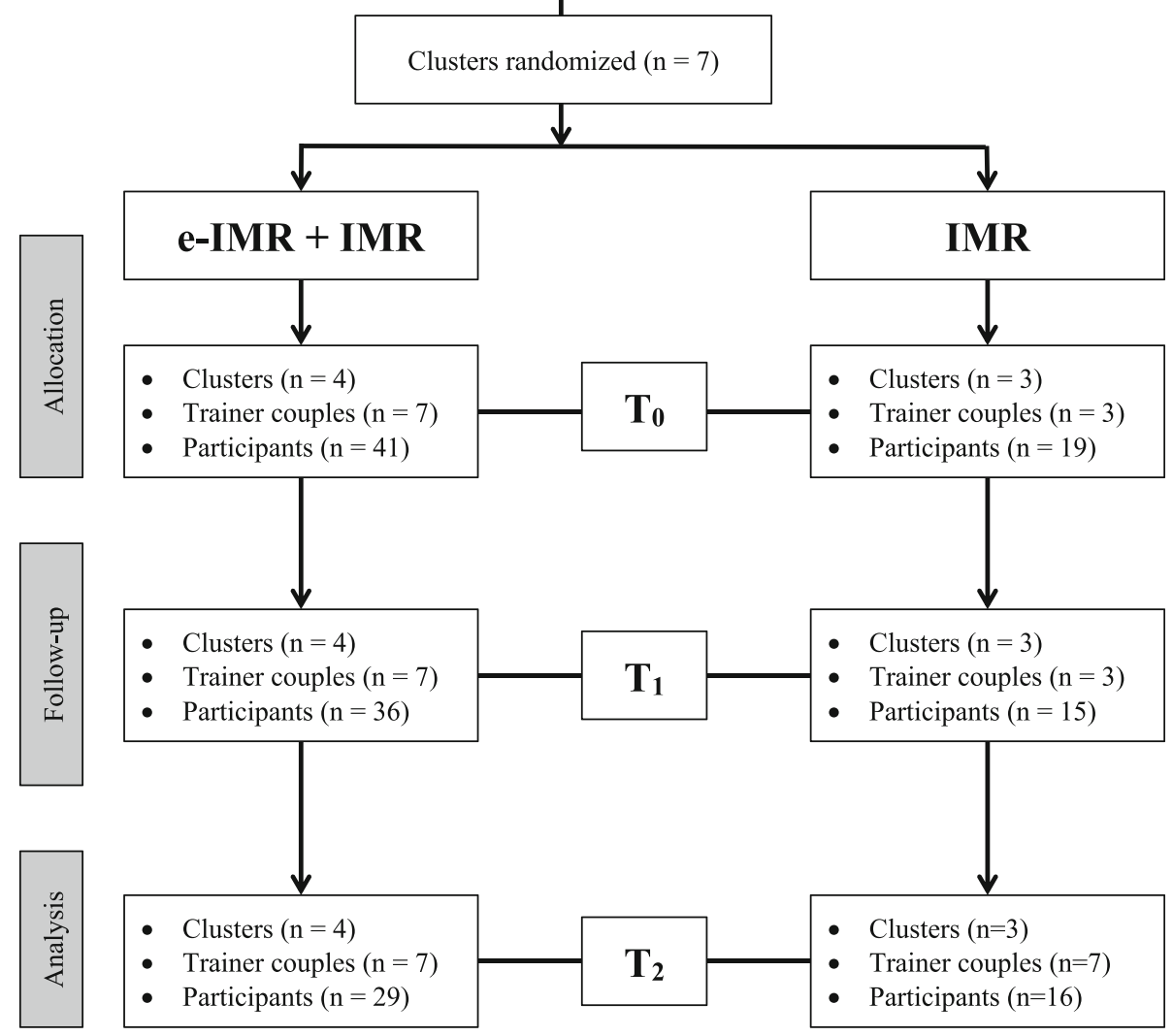

Fig. 1 Participants flow diagram through the study 
Non-completion of the face-to-face IMR-programme sessions was expected to interact with the effects because being a non-completer is correlated to lower functioning; for instance, lower social functioning [36] and higher emergency room visits and hospitalization [37]. In addition, we searched for correlations in $\mathrm{T}_{0}$ scores between the groups of completers and non-completers.

Because of the known low adherence-rate to Web-based interventions [5], additional subgroup analyses were performed within the intervention group to investigate whether actual use compared to non-use of the e-IMR leads to outcome differences. Thus in model 4 , two groups of e-IMR users and non-users were included according to the aforementioned adherence measurement.

\section{Results}

\section{Participant flow}

Nine institutions with potentially 15 clusters were screened for eligibility. Two clusters were not eligible because they did not deliver the IMR-programme as a whole. Two clusters did not start an IMR-programme

Table 1 Demographic and clinical characteristics at baseline per group

\begin{tabular}{|c|c|c|}
\hline \multirow[t]{3}{*}{ Variables } & Intervention group & Control group \\
\hline & n (\% within group) & $\mathrm{n}$ (\% within group) \\
\hline & Mean (SD) & Mean (SD) \\
\hline Participants & 41 & 19 \\
\hline Age & $46.9(11.6)$ & 40.7 (10.6) \\
\hline \multicolumn{3}{|l|}{ Gender $^{* *}$} \\
\hline Female & $30(73.2)$ & $6(31.6)$ \\
\hline Male & $11(26.8)$ & $13(68.4)$ \\
\hline \multicolumn{3}{|l|}{ Diagnoses } \\
\hline Psychotic disorders & $14(34.1)$ & $6(31.6)$ \\
\hline Mood/anxiety disorders & $15(36.6)$ & $10(52.6)$ \\
\hline Other disorders & $12(29.3)$ & $3(15.8)$ \\
\hline Global Assessment of Functioning & $50.86(8.2)$ & $49.8(10)$ \\
\hline Having a somatic comorbidity & $23(56.1)$ & $7(36.8)$ \\
\hline Having a psychiatric comorbidity & $27(65.9)$ & $11(57.9)$ \\
\hline \multicolumn{3}{|l|}{ Treatment history } \\
\hline Years ago since first treatment & $17.15(12.3)$ & $16.17(9.9)$ \\
\hline Number of admissions & $4.15(3.9)$ & $3.94(3.3)$ \\
\hline Never admitted & $7(17)$ & $2(10.5)$ \\
\hline \multicolumn{3}{|l|}{ Cultural Background } \\
\hline Dutch & $37(90.2)$ & $19(100)$ \\
\hline Turkish, Maroc, Surinam, or English & $4(9.8)$ & $0(0)$ \\
\hline \multicolumn{3}{|l|}{ In/outpatients ${ }^{*}$} \\
\hline Independent living & $30(73.2)$ & $8(42.1)$ \\
\hline Supported housing & $11(26.8)$ & $11(57.9)$ \\
\hline \multicolumn{3}{|l|}{ Netto income } \\
\hline$\leq$ Minimal income & $31(75.6)$ & $16(84.2)$ \\
\hline$>$ Minimal income & $10(24.4)$ & $3(15.8)$ \\
\hline \multicolumn{3}{|l|}{ Highest graduated education } \\
\hline$\leq$ Middle school & $26(63.4)$ & $12(63.2)$ \\
\hline$\geq$ High school & $15(36.6)$ & $7(36.8)$ \\
\hline \multicolumn{3}{|l|}{ Computer availability / usage } \\
\hline I don't have a computer/laptop & $8(19.5)$ & $3(15.8)$ \\
\hline I never use a computer/laptop & $6(14.6)$ & $2(10.5)$ \\
\hline
\end{tabular}


group. Four clusters declined because of organizational problems. Seven clusters were included: four were allocated to the intervention group and three to the control group. In three intervention clusters, a second trainer-couple started a second IMR group. So in total, ten IMR-programme groups (seven in the intervention and three in the control group) trained 60 participants: 41 in the intervention and 19 in the control group (see Fig. 1).

Table 1 shows baseline characteristics and distribution over the two groups. The characteristics 'gender' and 'inpatients/outpatients' were unequally distributed over the groups, $p=.002$ and $p=.02$ respectively.

All ten IMR-programme groups completed the trial. In the intervention group, 12 out of 41 participants were lost in the follow-up measures in the study. We lost five at $\mathrm{T}_{1}$ and another seven at $\mathrm{T}_{2}$. In the control group, four out of 19 participants were lost in the follow-up at $\mathrm{T}_{1}$ and $T_{2}$. We have missing data at $T_{1}$ for one participant in the control group. Participants either refused to be interviewed because of being too burdened by the interviews, or they did not respond to attempts to get in touch with them. Out of the 60 participants, 51 (36 and 15) participants were interviewed at $T_{1}$, and 45 at $T_{2}(29$ and 16) (See Fig. 1).

Out of the total of 60 participants, eighteen $(30 \%)$ were identified as a non-completer: participants who attended the face-to-face IMR programme sessions less than $50 \%$. Eight participants $(20 \%)$ in the intervention group and ten participants (58\%) in the control group were non-completers, which differed significantly ( $p$ $=.01$ ). Of these non-completers, 14 participants entered the intention-to-treat analyses, eight in the intervention group and six in the control group at $\mathrm{T}_{1}$, and seven in both groups at $\mathrm{T}_{2}$.
Out of the 41 participants in the intervention group, $23(56.1 \%)$ logged in on the e-IMR platform, twelve of whom completed the first online module and eight of whom visited the symptom-monitoring page (See Fig. 2). In total, 14 (34.1\%) participants were identified as e-IMR users.

\section{Outcomes and estimation}

The mean scores and standard deviations of the outcomes in both groups are presented in the Additional file 1 . Since the random effect of cluster was zero in nearly all the analyses, this factor was excluded from the analyses models. The relevant results of the mixed model analyses are shown in Table 2 . In model 1 , the participants in the intervention group scored significantly higher compared to the control group for the measures PAM-13 $(p=.01)$, MHRM $(p=.02)$, and Rand-RLEP $(p=.03)$ at $\mathrm{T}_{1}$, which faded at $\mathrm{T}_{2}$. At $\mathrm{T}_{2}$, the effect on the Rand-GHP was significant $(p=.02)$ in favour of the intervention group.

\section{Post hoc analyses}

In model 2, the analyses accounting for the covariate gender showed that the significant effects above could be explained by confounding except for the remaining effect for PAM-13 $(\mathrm{p}=.01)$ at $\mathrm{T}_{1}$. At $\mathrm{T}_{0}$, male participants scored significantly higher on nearly all the measures except for the PAM-13. The same exception occurred in the time trends, but contrarily in favour of female participants.

In model 3, the analyses showed that the interaction of the covariate non-completer was significant for the measures: PAM-13, $(\mathrm{p}=.03)$ and Rand-V $(\mathrm{p}=.03)$ at $\mathrm{T}_{1}$, which faded at $\mathrm{T}_{2}$. As an illustration of the interaction, the graphic in Fig. 3 shows the scores for the PAM-13,

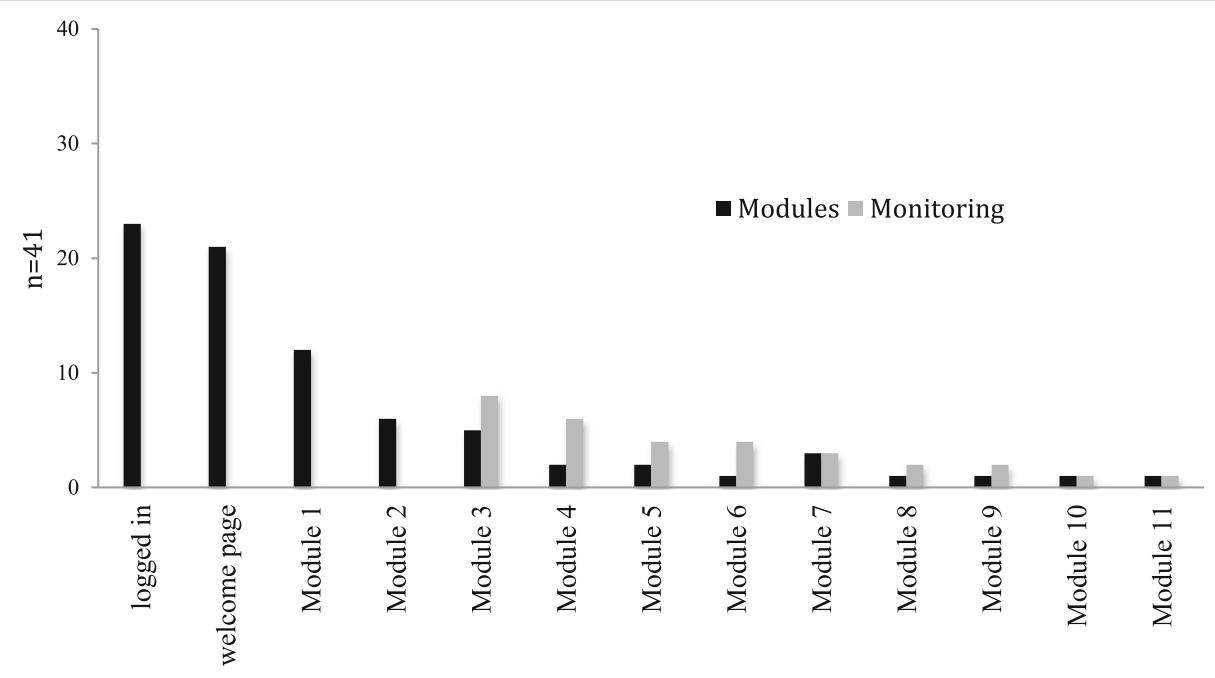

Fig. 2 Number of participants active on the e-IMR platform within the intervention group 


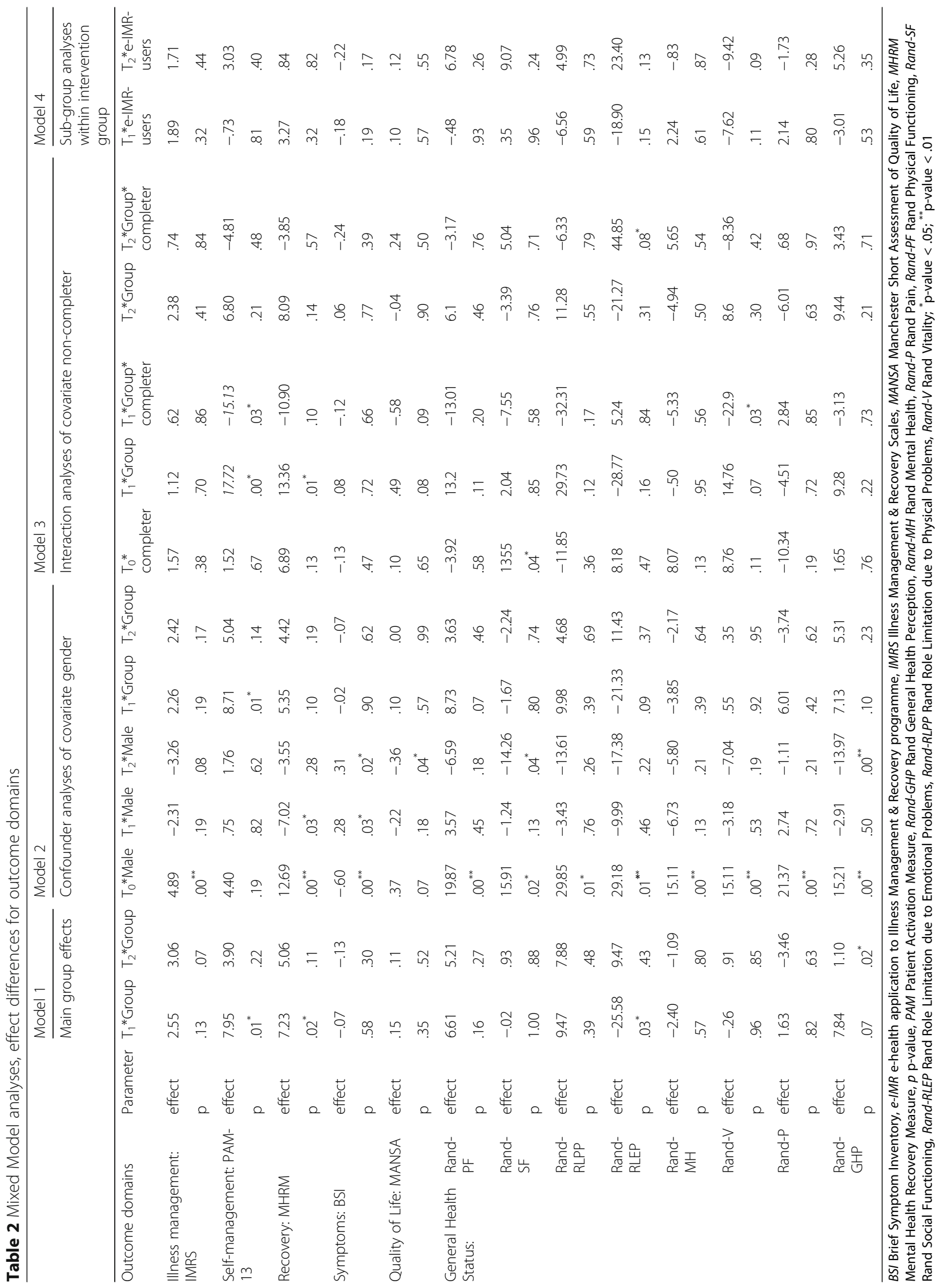




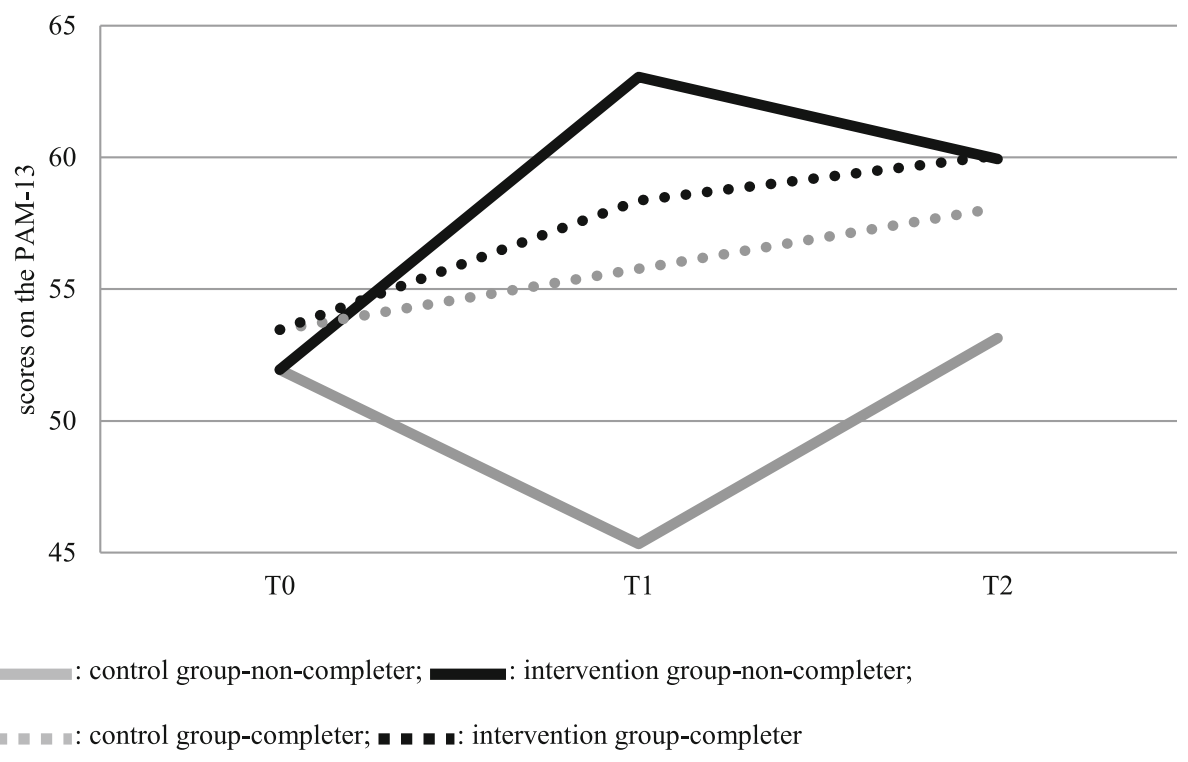

Fig. 3 The course of PAM-13 scores in analysis with covariate non-completer

which resembles the scores of the Rand-V. We did not find significant correlations in PAM-13 scores at $\mathrm{T}_{0}$ between the completers and non-completers $(p=.77)$.

In model 4 , the subgroup analyses within the intervention group between the groups of e-IMR users and non-users showed no significant effect differences at $\mathrm{T}_{1}$ and $\mathrm{T}_{2}$.

\section{Harm}

No serious adverse events were reported during the trial.

\section{Discussion}

This study shows significant differences in main effects for the parameters self-management (PAM-13), recovery (MHRM), and role limitation due to emotional problems (Rand-RLEP) in favour of the intervention group at $T_{1}$, which faded at $T_{2}$. At $T_{2}$, a significant effect for general health perception (Rand-GHP) occurred, also in favour of the intervention group.

Post hoc analyses showed that the confounder gender explained the effects for recovery and role limitation due to emotional problems at $T_{1}$, and for general health perception at $\mathrm{T}_{2}$. The confounding effects of gender were based on three types of differences: first, the baseline distribution showed significantly more females in the intervention group; second, at $\mathrm{T}_{0}$ males scored significantly higher on most of the measures; and third, time trends were in favour of female participants. In general, women do differ from men in a number of ways; for instance, exposure and reactions to stress [35], needs and care [38, 39], and coping styles [40]. With regard to coping styles, women could benefit more from a problem-solving-focused intervention and men from an emotion-focused one [41]. IMR, with its emphasis on learning how to manage an illness in a context of pursuing recovery goals [42], has a greater focus on problemsolving- than on emotional strategies. Therefore, women could have benefitted more from the IMR-programme than men.

Post-hoc analyses showed that the confounder gender did not explain the effects for the parameter self-management. Also in studies with people with diabetes II [43] and other chronic illnesses [44], no relations were found between gender and self-management, measured by the PAM-13.

The interaction covariate non-completer significantly modified the effect for the parameter self-management (PAM) and vitality (Rand-V) such that a large intervention effect was seen in the non-completers and a small effect in the completers. Apparently, stopping the IMR-programme was based on differences in their improvements. In this study, improvements in conditions of people who dropped out of the IRM-programme were unequally distributed over the groups, which modified the effects. The unlikeliness of the effects is confirmed by the subgroup analyses within the intervention group which showed no significant effect differences between the groups of e-IMR users and non-users.

A last issue to discuss is the low use of the e-IMR platform by the participants in the intervention group which resulted in a minor contrast in the treatments provided to the participants in the intervention and control group and further calls into question the validity of ascribing the effects observed to the e-IMR. The modest use of the e-IMR matches with $6 \%$ of consumers using e-health in general mental health in the year of this study [45]. 
A number of limitations should be noted. Unfortunately, the planned sample size was not achieved and a lower number of participants entered the control group. This might have caused the unequal distribution of some covariates. Due to the small sample, we could not control for more than one covariate in the mixed models without risking overfitting. Notwithstanding the small sample, a number of non-completers did not withdraw from the study. The overall non-completer rate of $30 \%$ is similar to other IMR studies [7]. Therefore, the intention-to-treat analyses resemble normal practice.

\section{Conclusion}

Finally, this study precludes definite conclusions on the potential efficacy of e-health for people with SMI. This leaves us with many questions about the barriers and facilitators of the e-IMR intervention and its implementation. Against the backdrop of the great promise of e-mental health [46], the modest use of the e-IMR platform might be an interesting outcome which needs to be further investigated. Before deciding how to continue studying the effectiveness of e-IMR, we will investigate barriers and facilitators of the e-IMR and its implementation.

\section{Additional files}

Additional file 1: Mean scores and standard deviation of the outcome domains per group at baseline $\left(T_{0}\right)$, halfway $\left(T_{1}\right)$ and post treatment $\left(T_{2}\right)$ (DOCX $29 \mathrm{~kb}$ )

\section{Abbreviations}

BSI: Brief Symptom Inventory; e-IMR: e-health application to IIIness Management \& Recovery programme; IMR: IIIness Management \& Recovery programme; IMRS: IIIness Management \& Recovery Scales; MANSA: Manchester Short Assessment of Quality of Life; MHRM: Mental Health Recovery Measure; PAM13: Patient Activation Measure; Rand-GHP: Rand General Health Perception; Rand-MH: Rand Mental Health; Rand-P: Rand Pain; Rand-PF: Rand Physical Functioning; Rand-RLEP: Rand Role Limitation due to Emotional Problems; Rand-RLPP: Rand Role Limitation due to Physical Problems; Rand-SF: Rand Social Functioning; Rand-V: Rand Vitality; SMI: Severe (or Serious) Mental IIIness; $T_{0}$ : Time point 0 , baseline; $T_{1}$ : Time point 1 , halfway, after completing the 5 th module; $T_{2}$ : Time point 2, endpoint, at least a week after finishing the IMRprogramme

\section{Acknowledgements}

Not applicable.

\section{Funding}

This study was funded by the ZonMW (the Netherlands Organisation for Health Care Research and Development) programme Tussen Weten en Doen' (Grant 520001001). The funder had no influence on study design, the collection, analysis and interpretation of the data, the writing of the report, and the decision to submit the article for publication.

\section{Availability of data and materials}

Data and materials will be made available after a request to the corresponding author.

\section{Authors' contributions}

TB., PG, ST, MN and BVG contributed to the conception and design of the study. TB contributed to the data collection. All authors contributed to the analysis and interpretation, and provided drafting of the article. All authors contributed to the critical revision of the article for important intellectual content and final approval of the article.

\section{Ethics approval and consent to participate}

Individuals who were referred to the IMR-programme were informed about the trial by their case manager. The researcher contacted those who expressed an interest individually and explained the trial and research activities. If they were still interested and eligible, the written consent to participate was signed. No incentives were provided. The ethical approval for conducting the e-IMR trial was provided by the Committee on Research Involving Human Subjects, Arnhem-Nijmegen (NL49693.091.14).

\section{Consent for publication}

Not applicable.

\section{Competing interests}

The authors declare that they have no competing interests.

\section{Publisher's Note}

Springer Nature remains neutral with regard to jurisdictional claims in published maps and institutional affiliations.

\section{Author details}

${ }^{1}$ Titus Beentjes, IQ Healthcare, Radboud University Medical Center, Radboud Institute for Health Sciences, PO Box 9101, 6500, HB, Nijmegen, the Netherlands. ${ }^{2}$ Center for Nursing Research, Saxion University of Applied Science, Deventer/Enschede, the Netherlands. ${ }^{3}$ Dimence Group Mental Health Care Centre, Deventer, the Netherlands. ${ }^{4}$ Department of Public Health, Faculty of Medicine and Health Sciences, University Centre for Nursing and Midwifery, Ghent University, Ghent, Belgium. ${ }^{5}$ Department for Health Evidence, Radboud University Medical Center, Radboud Institute for Health Sciences, Group Biostatistics, Nijmegen, the Netherlands. ${ }^{6}$ Faculty of Health and Social Studies, HAN University of Applied Sciences, Nijmegen, the Netherlands.

Received: 7 June 2018 Accepted: 23 November 2018

Published online: 12 December 2018

\section{References}

1. Ben-Zeev D, Drake RE, Corrigan PW, Rotondi AJ, Nilsen W, Depp C. Using contemporary Technologies in the Assessment and Treatment of serious mental illness. Am J Psychiatr Rehabil. 2012;15:357-76.

2. Naslund JA, Marsch LA, McHugo GJ, Bartels SJ. Emerging mHealth and eHealth interventions for serious mental illness: a review of the literature. J Ment Health. 2015;24:320-31.

3. van der Krieke L, Wunderink L, Emerencia AC, de Jonge P, Sytema S. Emental health self-management for psychotic disorders: state of the art and future perspectives. Psychiatr Serv. 2014;65:33-49.

4. Bremmer F, van Es M. Een analyse van de Verwachte Kosten En Baten van EHealth, blended Behandelen En Begeleiden [an analyses of the expected costs and benefits of e-health, blended treatment and care]. Amersfoort: GGZ Nederland; 2013.

5. Kelders SM, Kok RN, Ossebaard HC, Van Gemert-Pijnen JE. Persuasive system design does matter: a systematic review of adherence to web-based interventions. J Med Internet Res. 2012;14:e152.

6. Postel M, Witting M, van Gemert-Pijnen L. Blended behandeling in de geestelijke gezondheidszorg [Blended Treatment in Mental Health]. Dir Ther. 2013;33:210-21.

7. McGuire AB, Kukla M, Green A, Gilbride D, Mueser KT, Salyers MP. IIIness management and recovery: a review of the literature. Psychiatr Serv. 2014; 65:171-9.

8. Beentjes TAA, van Gaal BGI, Goossens PJJ, Schoonhoven L. Development of an e-supported illness management and recovery programme for consumers with severe mental illness using intervention mapping, and design of an early cluster randomized controlled trial. BMC Health Serv Res. 2016;16:20.

9. Craig P, Dieppe P, Macintyre S, Michie S, Nazareth I, Petticrew M. Developing and evaluating complex interventions: the new Medical Research Council guidance. Int J Nurs Stud. 2013;50:585-92. 
10. Delespaul PH, EPA d c. Consensus regarding the definition of persons with severe mental illness and the number of such persons in the Netherlands. Tijdschr Psychiatr. 2013;55:427-38.

11. Brugman M, Stalenhoef L, Kamman R, Meinen G. Illness Management \& Recovery 3.0. Enschede: Saxion; 2014.

12. Limesurvey. An Open Source survey tool. Germany: Limesurvey GmbH, Hamburg; 2012.

13. Mueser KT, Gingerich S, Salyers MP, McGuire AB, Reyes RU, Cunningham H. Illness Management and Recovery (IMR) Scales. In: Campbell-Orde T, Chamberlin J, Carpenter J, Leff HS, editors. Measuring the Promise: A Compendium of Recovery Measures Volume II: Cambridge, Human Services Research Institute; 2005. p. 32-5. \& 124-132.

14. Goossens PJJ, Beentjes TAA, Knol S, Salyers MP, de Vries SJ. Investigating the reliability and validity of the Dutch versions of the illness management and recovery scales among clients with mental disorders. J Ment Health. 2017; 26:489-95.

15. Salyers MP, Godfrey JL, Mueser KT, Labriola S. Measuring illness management outcomes: a psychometric study of clinician and consumer rating scales for illness self management and recovery. Community Ment Health J. 2007:43:459-80.

16. Hasson-Ohayon I, Roe D, Kravetz S. The psychometric properties of the illness management and recovery scale: client and clinician versions. Psychiatry Res. 2008;160:228-35.

17. Färdig R, Lewander T, Fredriksson A, Melin L. Evaluation of the illness management and recovery scale in schizophrenia and schizoaffective disorder. Schizophr Res. 2011;132:157-64.

18. Hibbard JH, Mahoney ER, Stockard J, Tusler M. Development and testing of a short form of the patient activation measure. Health Serv Res. 2005;40(6 Pt 1):1918-30.

19. Zill JM, Dwinger S, Kriston L, Rohenkohl A, Härter M, Dirmaier J. Psychometric evaluation of the German version of the patient activation measure (PAM13). BMC Public Health. 2013;13:1027.

20. Rademakers J, Nijman J, van der Hoek L, Heijmans M, Rijken M. Measuring patient activation in the Netherlands: translation and validation of the American short form patient activation measure (PAM13). BMC Public Health. 2012;12:577.

21. Moljord IEO, Lara-Cabrera ML, Perestelo-Pérez L, Rivero-Santana A, Eriksen L, Linaker OM. Psychometric properties of the patient activation Measure-13 among out-patients waiting for mental health treatment: a validation study in Norway. Patient Educ Couns. 2015;98:1410-7.

22. Green CA, Perrin NA, Polen MR, Leo MC, Hibbard JH, Tusler M. Development of the patient activation measure for mental health. Admin Pol Ment Health. 2010;37:327-33.

23. van Nieuwenhuizen C, Wilrycx G, Moradi M, Brouwers E. Psychometric evaluation of the Dutch version of the mental health recovery measure (MHRM). Int J Soc Psychiatry. 2014;60:162-8.

24. Bullock W. The mental health recovery measure (MHRM): Updated Normative Data and Psychometric Properties. Toledo: Department of Psychology, University of Toledo; 2009.

25. Derogatis $L R$, Melisaratos $N$. The brief symptom inventory-an introductory report. Psychol Med. 1983;13:595-605.

26. Beurs E, de ZF. De brief symptom inventory (BSI). De betrouwbaarheid en validiteit van een handzaam alternatief voor de SCL-90. [the brief symptom inventory, reliability and validity of a conveniant alternative]. Maandbl Geestelijke Volksgezond. 2006;61:120-41.

27. Priebe $S$, Huxley P, Knight S, Evans S. Application and results of the Manchester short assessment of quality of life (Mansa). Int J Soc Psychiatry. 1999:45:7-12.

28. Björkman T, Svensson B. Quality of life in people with severe mental illness. Reliability and validity of the Manchester short assessment of quality of life (MANSA). Nord J Psychiatry. 2005;59:302-6.

29. Hays RD, Sherbourne CD, Mazel RM. The RAND 36-item health survey 1.0. Health Econ. 1993;2:217-27.

30. van der Zee Kl, Sanderman R, Heyink JW, de Haes H. Psychometric qualities of the RAND 36-item health survey 1.0: a of multidimensional measure of general health status. Int J Behav Med. 1996;3:104-22.

31. McGuire AB, Bonfils KA, Kukla M, Myers L, Salyers MP. Measuring participation in an evidence-based practice: illness management and recovery group attendance. Psychiatry Res. 2013;210:684-9.

32. IBM C. IBM SPSS statistics for Macintosh, version 23; 2015.
33. Moher D, Hopewell S, Schulz KF, Montori V, Gotzsche PC, Devereaux PJ, Elbourne D, Egger M, Altman DG. CONSORT 2010 explanation and elaboration: updated guidelines for reporting parallel group randomised trials. BMJ. 2010;340(mar23 1):c869.

34. Portney L, Watkins M. Foundation of Clinical Research, application to practice. 3rd ed. Upper Sadle River, New Jersey: Pearson education, Inc.; 2009.

35. Mayor E. Gender roles and traits in stress and health. Front Psychol. 2015;6:1-7.

36. Lincoln TM, Rief W, Westermann S, Ziegler M, Kesting ML, Heibach E, Mehl S. Who stays, who benefits? Predicting dropout and change in cognitive behaviour therapy for psychosis. Psychiatry Res. 2014;216:198-205.

37. Salyers MP, Rollins AL, Clendenning D, McGuire AB, Kim E. Impact of illness management and recovery programs on hospital and emergency room use by Medicaid enrollees. Psychiatr Serv. 2011;62:509-15.

38. Arvidsson H. Gender differences in needs and care of severely mentally ill persons: findings from a Swedish cross-sectional and longitudinal study. Int J Soc Psychiatry. 2010;56:424-35.

39. Manuel Jl, Stebbins MB, Wu E. Gender differences in perceived unmet treatment needs among persons with and without co-occurring disorders. J Behav Health Serv Res. 2018;45:1-12.

40. Turner H, Bryant-Waugh R, Peveler R, Bucks RS. A psychometric evaluation of an English version of the Utrecht coping list. Eur Eat Disord Rev. 2012;20:339-42.

41. Schut HA, Stroebe MS, van den Bout J, de Keijser J. Intervention for the bereaved: gender differences in the efficacy of two counselling programmes. Br J Clin Psychol. 1997;36(Pt 1):63-72.

42. Mueser KT, Meyer PS, Penn DL, Clancy R, Clancy DM, Salyers MP. The illness management and recovery program: rationale, development, and preliminary findings. Schizophr Bull. 2006;32(Suppl 1):S32-43.

43. Hendriks SH, Hartog LC, Groenier KH, Maas AHEM, van Hateren KJJ, Kleefstra $\mathrm{N}$, Bilo HJG. Patient activation in type 2 diabetes: does it differ between men and women? J Diabetes Res. 2016;2016:1-8.

44. Rijken M, Heijmans M, Jansen D, Rademakers J. Developments in patient activation of people with chronic illness and the impact of changes in selfreported health: results of a nationwide longitudinal study in the Netherlands. Patient Educ Couns. 2014;97:383-90.

45. Krijgsman J, Peeters J, Burghouts A, Brabers A, De Jong J, Moll T, Friele R, Van Gennip L. Tussen vonk en vlam e-health-monitor 2015 [Dutch E-health monitor 2015]. Den Haag: Nictiz \& NIVEL; 2015.

46. WHO. The European Mental Health Action Plan 2013-2020. Copenhagen: WHO; 2013.

\section{Ready to submit your research? Choose BMC and benefit from:}

- fast, convenient online submission

- thorough peer review by experienced researchers in your field

- rapid publication on acceptance

- support for research data, including large and complex data types

- gold Open Access which fosters wider collaboration and increased citations

- maximum visibility for your research: over $100 \mathrm{M}$ website views per year

At BMC, research is always in progress.

Learn more biomedcentral.com/submissions 